\title{
DESPESAS EM AÇÕES DA ASSISTÊNCIA FINANCEIRA DA UNIÃO NA EDUCAÇÃO BÁSICA NO PERÍODO 2014-2020
}

\author{
EXPENSES IN FINANCIAL ASSISTANCE ACTIONS FROM THE UNION IN K-12 \\ EDUCATION BETWEEN 2014 AND 2020
}

\author{
GASTO EN AYUDA FINANCIERA DEL GOBIERNO FEDERAL EN EDUCACIÓN \\ BÁSICA EN EL PERÍODO 2014-2020
}

\author{
Nalú Farenzena \\ Doutora em Educação \\ Professora titular da Universidade Federal do Rio Grande do Sul \\ nalu.farenzena@gmail.com
}

\begin{abstract}
Resumo: Uma das responsabilidades do governo da União no setor educacional é a prestação de assistência técnica e financeira aos governos subnacionais na educação básica, responsabilidade que é um dos pilares da cooperação federativa na educação e da atuação estatal para a garantia dos direitos à educação. O objetivo do artigo é analisar a evolução da execução orçamentária nas principais ações de assistência financeira do governo federal na educação básica entre os anos de 2014 e 2020, de responsabilidade, do Fundo Nacional de Desenvolvimento da Educação (FNDE) e da Fundação Coordenação de Aperfeiçoamento de Pessoal de Nível Superior (Capes). São trabalhados os montantes, totais e por agrupamentos, de ações orçamentárias, bem como os valores por matrícula, considerando os demarcadores para a atuação da União na educação básica: as funções supletiva e redistributiva e os objetivos de garantia de padrão de qualidade e equalização de oportunidades educacionais. No período, ocorreu decréscimo de recursos, no total e na grande maioria das ações, o que deriva, principalmente, da política de austeridade fiscal posta pela Emenda à Constituição no 95/2016, que fixou um teto para os gastos primários federais. A complementação da União ao Fundeb e o Programa Nacional de Apoio ao Transporte do Escolar são as ações com menor diminuição de recursos dentro do período, porém, houve significativas perdas em outras ações, principalmente naquelas de assistência voluntária.
\end{abstract}

Palavras-chave: assistência financeira da União na educação; cooperação federativa na educação; financiamento da educação básica; políticas de financiamento da educação.

\begin{abstract}
One of the responsibilities of the federal government in the educational sector is to provide technical and financial assistance to the subnational governments in K-12 education. This responsibility is one of the pillars of the federative cooperation in education and the state work to guarantee the rights to education. The aim of the paper is to analyze the evolution of the budgetary execution in the major financial assistance actions from the federal government in K-12 education between 2014 and 2020, a responsibility of the National Fund for Educational Development (FNDE) and the Coordination for the Improvement of Higher Education Personnel (Capes). It is analyzed the total and per group sums of budgetary actions, as well as the values per enrollment, considering the border-settlings for the Union work in K-12 education: the supplementary and redistributive functions and the goals of warranting quality standard and the equalizing of educational opportunities. In the period, there was a decrease of total resources and in most of the actions, mainly resulting from the fiscal austerity policy imposed by the Amendment N. 95/2016 to the Constitution, which established an expenditure ceiling for the federal primary expenses. The Union supplementation to the Fund for the Development of Basic Education and Appreciation of the Teaching Profession (Fundeb) and the National Program for Support to Student Transportation are the actions with the least decrease in resources within the period. However, there were significant losses in other actions, mainly the voluntary assistance ones.
\end{abstract}

Keywords: financial assistance from the Union in education; federative cooperation in education; K-12 education funding; education funding policies.

Resumen: Una de las responsabilidades del gobierno federal de Brasil en el sector educativo es brindar asistencia técnica y financiera a los gobiernos de los estados y municipalidades en educación básica, responsabilidad que es uno de los pilares de la cooperación federativa en educación y de la acción estatal para garantizar los derechos a la educación. El objetivo del artículo es analizar la evolución de la ejecución presupuestaria en las principales acciones de asistencia financiera del gobierno federal en educación básica entre 2014 y 2020, bajo la responsabilidad del Fondo Nacional de Desarrollo Educativo (FNDE) y la Fundación Coordinación de Mejoramiento de Personal de Educación Superior (Capes). Se elaboran los montos, totales y por agrupaciones, de las acciones presupuestarias, así como los valores por matrícula, considerando las demarcaciones del rol de la Unión en educación básica: las funciones complementarias y redistributivas y los objetivos de garantizar un estándar de calidad y equidad de oportunidades educativas. Durante el período, hubo una disminución de los recursos, en total y en la gran mayoría de las acciones, que se deriva principalmente de la política de austeridad fiscal introducida por la Reforma a la Constitución $n^{\circ}$ 95/2016, que fijó un tope para el gasto primario federal. La complementación al Fondo de Mantenimiento y Desarrollo de la Educación Básica y de Valorización de los Profesionales de la Educación (Fundeb) y el Programa Nacional de Apoyo al Transporte Escolar son las acciones con menor reducción de recursos en el período, sin embargo, hubo pérdidas significativas en otras acciones, principalmente las de asistencia voluntaria

Palabras clave: ayuda financiera del gobierno federal en educación; cooperación federativa en educación; financiamiento de la educación básica; políticas de financiación de la educación.

Para citar - (ABNT NBR 6023:2018)

FARENZENA, Nalú. Despesas em ações da assistência financeira da União na educação básica no período 2014-2020. Eccos - Revista Científica, São Paulo, n. 58, p. 1-17, e20849, jul./set. 2021. Disponível em: https://doi.org/10.5585/eccos.n58.20849. 


\section{Introdução}

$\mathrm{Na}$ organização nacional da educação brasileira, incumbe ao governo da União assistir técnica e financeiramente aos municípios, aos estados e ao Distrito Federal. Na educação básica, esta incumbência da União, conjugada com as responsabilidades e prioridades dos governos subnacionais, é parte da configuração institucional e da prática da colaboração entre os sistemas de ensino e da cooperação entre governos, ou seja, da atuação do Estado para a garantia dos direitos educacionais.

Sendo parte, por conseguinte, do federalismo educacional brasileiro, o estudo das normas e da implementação da política de assistência técnica e financeira do governo da União ganha relevância, sobretudo tendo em conta as profundas desigualdades socioeducacionais do país, e suas diversas dimensões ou recortes, bem como as desigualdades e especificidades de capacidade financeira e técnico-administrativa dos milhares de governos que se ocupam do setor. Sim, são 26 governos estaduais, um governo do Distrito Federal e 5.568 governos municipais. Os programas federais PNAE e o PDDE Básico, de caráter universal, podem beneficiar, potencialmente, mais de 40 milhões de educandos e educandas que frequentam escolas públicas municipais e estaduais ou escolas privadas sem fins lucrativos conveniadas com algum governo.

Diante desta configuração, o objetivo deste artigo é analisar a evolução da execução orçamentária nas principais ações de assistência financeira do governo federal na educação básica entre os anos de 2014 e 2020. Como grande parte da assistência financeira é de responsabilidade, na execução, do Fundo Nacional de Desenvolvimento da Educação (FNDE) e da Fundação Coordenação de Aperfeiçoamento de Pessoal de Nível Superior (Capes), são consideradas ações orçamentárias das duas autarquias.

O período foi definido com o intuito de abranger diferentes governos, compreendendo uma parte, ou todo o mandato, da Presidenta Dilma Vana Rousseff, do Presidente Michel Temer e do Presidente Jair Messias Bolsonaro. Foi considerado suficiente abarcar este período de sete anos, pois contempla contextos políticos e econômicos diversos e que demarcam as tendências mais recentes da política federal de assistência financeira à educação básica.

$\mathrm{O}$ artigo contém cinco seções, além desta introdução. Na segunda são explicitados o enfoque do financiamento da educação como política pública e a compreensão de política e políticas de assistência da União na educação. Na sequência, de modo bastante sucinto é descrita a política de austeridade fiscal, pelo impacto que tem na política que é objeto deste texto. Na quarta seção são analisadas as ações orçamentárias do FNDE e da Capes de assistência 
financeira na educação básica, apresentando-se valores monetários organizados em distintos agrupamentos. No comentário final são comentados desafios e efeitos da diminuição de recursos federais de assistência nas demandas aos governos subnacionais.

\section{Aspectos metodológicos: o olhar sobre o financiamento público da educação e assistência da União na educação básica}

Este artigo resulta de pesquisa mais ampla sobre a política de assistência financeira da União na educação básica, na qual o financiamento da educação é compreendido como política pública.

Política pública conceituada como ação do Estado, dos agentes estatais ou de atores com autoridade delegada pelo Estado: “O conceito designa as intervenções de uma autoridade investida de poder público e de legitimidade governamental sobre um setor específico da sociedade ou de um território. [...]. Elas mobilizam atividades e processos de trabalho.” (THOENIG, 2006, p. 328). As políticas públicas, como dispositivos político-administrativos (MULLER, 2006), exigem mobilização, para decisões e ações, e, por isso, têm uma dimensão de concretude, de tradução de prescrições em atos para manter ou alterar uma situação. O mesmo autor argumenta que cada política busca agir sobre um setor da sociedade, em geral para transformar ou adaptar uma situação. Essa ação passa pela definição de objetivos e essa é forjada a partir de uma representação, uma significação, de um problema e de suas consequências, assim como das alternativas de intervenção. As políticas públicas podem ser vistas como processos através dos quais são elaboradas as representações que uma sociedade constrói para compreender e agir sobre o real, tal qual ele é percebido; seriam formas de uma sociedade construir sua relação com o mundo, ou seja, são eivadas de disputas em que visões de mundo também se fazem presentes.

Lascoumes e Le Galès (2007) propõem um modelo de análise para o estudo da ação pública, partindo da concepção de que uma política pública compreende cinco elementos (o pentágono da ação pública): atores, instituições, representações, processos e resultados. Todos estes elementos se fazem presentes na política de assistência financeira da União à educação básica.

Desde os conceitos de políticas públicas como dispositivos político-administrativos (MULLER, 2006), ou como formas de regulação social e política (LASCOUMES; LE GALÈS, 2007), pode-se olhar para o financiamento público da educação como ação pública ou política pública situada em zonas de interseção de setores estatais. Como policie, o financiamento público da educação condensa alternativas delineadas, em grande parte, no cruzamento de referenciais de política educacional e de finanças públicas e balizadas por regras institucionais de organização do 
Estado e do setor da educação, bem como pelas relações políticas mais amplas e aquelas setoriais. Ou seja, enfocar o financiamento público da educação como política pública também requer a consideração de estratégias e de interesses materiais e simbólicos dos atores, de instituições e de ideias (referenciais, visões de mundo), de processos e de resultados, dimensões sempre imbricadas na construção das policies. O financiamento das ações públicas é um meio para a consecução de ações, mas tem especificidades político-institucionais que justificam um recorte dentro de setores mais amplos que são a educação e as finanças públicas ${ }^{1}$.

Dentre as políticas de financiamento público da educação, o presente artigo enfoca políticas (programas, ações) de assistência financeira da União na área educacional, implementadas em cooperação com redes estaduais e municipais de ensino. Estas políticas, por sua vez, podem ser interpretadas como conformadoras da política concreta de assistência financeira da União, o que é parcialmente contemplado com o exame da evolução orçamentária entre 2014 e 2020. Esta compreensão de política, para ser mais completa, precisaria reunir outros elementos, por exemplo, as regras e as práticas político-administrativas de distribuição federativa dos recursos, e as características de cada Programa/Ação. Este texto, porém, se limita ao recorte já explicitado.

No art. 211 da Constituição da República, o parágrafo $1^{\circ}$ preceitua as responsabilidades da União na Educação:

\begin{abstract}
A União organizará o sistema federal de ensino e o dos Territórios, financiará as instituições de ensino públicas federais e exercerá, em matéria educacional, função redistributiva e supletiva, de forma a garantir equalização de oportunidades educacionais e padrão mínimo de qualidade do ensino mediante assistência técnica e financeira aos Estados, ao Distrito Federal e aos Municípios (BRASIL, 1988, grifos meus).
\end{abstract}

Além das atribuições para com a rede pública federal, é incumbência da União a assistência financeira e técnica aos governos subnacionais, com objetivos e funções definidos. As funções - supletiva e redistributiva - e os objetivos - garantia de maior equidade nas oportunidades educacionais e de padrão mínimo de qualidade do ensino - sempre devem estar presentes quando se examina a prática da assistência, pois lhe colocam uma circunscrição em termos de critérios e finalidades ${ }^{2}$. Recentemente, com a aprovação da Emenda $n^{\mathbf{o}} 108$ à Constituição Federal, foi acrescido ao art. 211 o parágrafo $7^{\circ}$, o qual preceitua que o padrão mínimo de qualidade a ser garantido pela União deve considerar as condições adequadas de oferta e ter como referência o Custo Aluno Qualidade (CAQ). Tal mandamento

\footnotetext{
${ }^{1}$ A respeito do financiamento da educação como política pública, ver também Martins (2010).

${ }^{2}$ Detalhamentos de conceitos e noções acerca de assistência técnica, assistência financeira e funções supletiva e redistributiva podem ser encontrados em Cruz (2009), Cavalcanti (2016, 2019), Farenzena (2012a, 2012b).
} 
constitucionaliza preceitos de estratégias da Meta 20 do PNE - Plano Nacional de Educação (Lei $\mathrm{n}^{\circ}$ 13.005/2014) - e sua regulamentação poderá representar um grande passo no sentido da efetivação das funções e objetivos da assistência da União na educação. Por ora, como se verá nos dados mais adiante apresentados, os recursos da assistência financeira são reduzidos e, pior que isso, "Em que pese ser indispensável o que tem sido efetivado como assistência técnica e financeira da União às redes estaduais e municipais da Educação Básica, o montante de recursos tem decrescido nos anos mais recentes, comprometendo enormemente suas funções e objetivos" (FINEDUCA, 2021, p. 43).

No Quadro 1 é apresentada uma classificação que abrange tanto a assistência técnica quanto a financeira e cujo critério de agrupamento é a natureza de institucionalização das ações: programas e ações que são obrigatórios, tradicionais e voluntários. É de observar que, as ações de assistência financeira, cuja execução é abordada na quarta seção deste artigo, na sua maioria envolvem também assistência técnica, como as de formação, planejamento, critérios e procedimentos de implementação, monitoramento e avaliação.

Quadro 1 - Tipos de assistência da União aos estados e municípios na educação básica conforme a obrigatoriedade legal ou não da ação - 2020

\begin{tabular}{|c|c|c|}
\hline $\begin{array}{l}\text { Assistência Obrigatória: } \\
\text { recursos financeiros }\end{array}$ & $\begin{array}{l}\text { Assistência Voluntária } \\
\text { "Tradicional" }\end{array}$ & Assistência Voluntária \\
\hline $\begin{array}{l}\text { Transferência de recursos } \\
\text { financeiros para governos ou } \\
\text { escolas. } \\
\text { Complementação ao Fundeb; } \\
\text { Programa Nacional de } \\
\text { Alimentação Escolar (Pnae), } \\
\text { Programa Dinheiro Direto na } \\
\text { Escola (PDDE Básico), } \\
\text { Programa Nacional de Apoio } \\
\text { ao Transporte do Escolar } \\
\text { (Pnate), Programa de Apoio } \\
\text { aos Sistemas de Ensino para } \\
\text { Atendimento à Educação de } \\
\text { Jovens e Adultos; Programa } \\
\text { Brasil Alfabetizado, Apoio à } \\
\text { Manutenção da Educação } \\
\text { Infantil e Apoio à Implantação } \\
\text { da Educação Infantil. }\end{array}$ & $\begin{array}{l}\text { Aquisição e distribuição de } \\
\text { livros e de materiais didáticos. } \\
\text { Programa Nacional do Livro e } \\
\text { do Material Didático (PNLD), } \\
\text { Programa Nacional Biblioteca } \\
\text { na Escola (PNBE). }\end{array}$ & $\begin{array}{l}\text { Assistência técnica ou financeira } \\
\text { não prevista no ordenamento legal } \\
\text { Exemplos: Apoio à Infraestrutura } \\
\text { para a Educação Básica, Caminho } \\
\text { da Escola, kits de materiais, Ações } \\
\text { Integradas do PDDE, programas } \\
\text { de formação (professores e outros } \\
\text { profissionais da educação, } \\
\text { conselheiros), disponibilização de } \\
\text { estudos, levantamentos, avaliações } \\
\text { e orientações. }\end{array}$ \\
\hline
\end{tabular}

Fonte: leis e normas dos programas e ações.

A assistência chamada de obrigatória é aquela prevista na Constituição Federal - a complementação da União ao Fundo de Manutenção e Desenvolvimento da Educação Básica e de Valorização dos Profissionais da Educação (Fundeb) - ou na legislação federativa, como são os casos do Pnae, do Pnate e do PDDE Básico, todos envolvendo assistência financeira e ações 
de assistência técnica interligadas (levantamentos, avaliações etc.) ${ }^{3}$. Há programas de assistência que se caracterizam pela compra e distribuição de bens, os quais, embora não previstos em lei, tornaram-se tradicionais, pelo qual seria muito difícil imaginar sua extinção (PNLD, PNBE); um terceiro grupo são as ações de assistência voluntária, que agrupam tanto assistência técnica quanto assistência financeira, grande parte incluída, atualmente, na política Plano de Ações Articuladas (PAR). Reitera-se que é difícil encontrar políticas de assistência financeira puras, que dizer, apenas com transferência de recursos financeiros; nessas, sempre há ações de assistência técnica previstas, voltadas à implantação ou qualificação das ações de suplementação financeira.

Antes de passar à análise dos dados, é descrita na continuidade, em linhas gerais, a política de austeridade fiscal no âmbito federal, pois é componente do contexto que impacta diretamente, e negativamente, a disponibilidade de recursos federais para a educação. O efeito do lamentável encolhimento das despesas federais é deletério não somente para a educação, mas para o conjunto das políticas sociais; com a crise sanitária e a agudização da crise econômica, decorrentes da pandemia de Covid-19, o efeito da agenda política da austeridade fiscal tem sido o aumento da pobreza e das desigualdades sociais; gastos extraordinários, por exemplo, com o auxílio emergencial ou Pronampe, não tem sido suficientes e sofrem grandes oscilações, expondo-se grave omissão estatal na garantia de direitos sociais e humanos.

\section{Algumas palavras sobre a política de austeridade fiscal}

Nos últimos cinco anos, posições de direita e conservadoras têm ganhado hegemonia na sociedade brasileira, contexto em que ocorre, no viés da política neoliberal, o aprofundamento do ajuste fiscal, a busca do desmonte de certos pilares da proteção social; no viés cultural, a disseminação de discursos e tortuosas ações neoconservadoras, com diversas implicações no setor educacional. Uma reflexão de O’Donnell (2010), escrita há mais de dez anos, sobre circunstâncias em que pode ocorrer a debilitação do Estado sob a vigência de regras da democracia política, é bastante atual para o Brasil. Ajustamentos promovidos pela via orçamentária repercutem penosamente a manutenção das instituições públicas federais de educação; uma profusão de reformulações, no campo orçamentário e para além dele, endereçadas à educação básica, em descompasso com a agenda do Plano Nacional de Educação 2014-2024, mobilizam cotidianamente esforços reativos dos atores alinhados com as pautas da democratização substantiva da educação.

\footnotetext{
A afirmação de que todas as ações citadas sejam "obrigatórias" é uma interpretação que leva em conta o critério de estarem previstas na Constituição da República ou em Lei, mesmo que o preceito seja de "autorização" para repasse de recursos.
} 
A austeridade fiscal, conforme Rossi et al (2019), pode ser assim conceituada: "política de ajuste da economia fundada na redução dos gastos públicos e do papel do Estado em suas funções de indutor do crescimento econômico e promotor do bem-estar social." Segundo os mesmos autores, a política de austeridade passou a fundamentar, de modo estrutural, as ações do setor público brasileiro com a promulgação da Emenda Constitucional (EC) nº 95/2016 .

A EC 95/2016 acresceu nove artigos ao Ato das Disposições Constitucionais Transitórias (ADCT) para impor um "Novo Regime Fiscal" aos orçamentos Fiscal e da Seguridade Social da União, com limites individualizados para despesas primárias do Executivo, do Judiciário, do Legislativo, do Ministério Público e da Defensoria Pública federais, pelo período de 20 anos, de 2017 a 2036. Usualmente, o Novo Regime Fiscal é chamado "Teto de Gastos". O Teto, em 2017, foi a despesa de 2016 corrigida em 7,2\% e, a partir de 2018, é o valor do limite do ano anterior atualizado pelo Índice Nacional de Preços ao Consumidor Amplo (IPCA).

O Teto de Gastos referente à regra de aplicação de, no mínimo, 18\% da receita resultante de impostos da União na manutenção e desenvolvimento do ensino passou a ter como referência, a partir de 2018, os "valores calculados para as aplicações mínimas do exercício imediatamente anterior" (art. 110, II do ADCT), corrigidos pelo IPCA. Ou seja, está suspenso, na vigência da EC 95/2016, o mínimo de $18 \%$ incidente sobre a receita líquida de impostos da União de cada exercício fiscal. A complementação da União ao Fundeb ficou excluída do Teto (Art. 107, parágrafo $6^{\circ}, \mathrm{I}$ do ADCT).

É de reafirmar, portanto, que a política de austeridade fiscal promovida pela EC 95/2016 atinge duramente a área da educação, sejam as despesas com a rede pública federal de ensino, seja com a assistência da União em programas e ações direcionados à educação básica das redes e escolas estaduais, municipais e do Distrito Federal. A complementação da União ao Fundeb não obedece ao Teto de Gastos, porém, pode-se cogitar, tendo em conta os dados de execução orçamentária da assistência financeira da União, que a proteção é contornada com alocação menor de recursos em outras ações, ou seja, um alinhamento à política mais geral de redução de gastos.

Nas palavras de Dweck, Rossi e Oliveira (2020, p. 11), o maior problema do Teto de Gastos primários da União foi "constitucionalizar uma redução do tamanho do Estado sem discussão prévia, e impor uma redução relativa dos pisos de financiamento para saúde e educação sem avaliar as necessidades de áreas tão caras à população.” Rossi et al. (2019),

\footnotetext{
${ }^{4} \mathrm{Na}$ obra citada, os autores explicam origens do termo austeridade, sua apropriação no campo econômico, o destaque que ganhou o referencial da austeridade a partir da crise econômica de 2008 , bem como a lógica da austeridade e seus mitos.
} 
estimaram que, de 2007 a 2037, o gasto primário da União retornará para um nível de 14\% do Produto Interno bruto (PIB), em contraposição ao período 1997-2017, quando de 14\% chegou a $19 \%$ do PIB; o projeto de país expresso na estimativa de regressão contrapõe-se à consolidação dos direitos sociais desenhada na Constituição de 1988. Os autores também estimaram os percentuais mínimos de gasto em MDE como proporção da receita líquida de impostos da União com a regra do Teto de Gastos: os 18\% cairiam para $16 \%$ em 2026 e $13 \%$ em 2016.

Segundo Pellanda e Cara (2020), o cumprimento das metas do Plano Nacional de Educação 2014-2024 fica inviabilizado com a política de austeridade fiscal; no sexto ano de vigência, em junho de 2020, 85\% das metas não tinham perspectiva de serem atingidas. Para a autora e o autor, as regras do Teto de Gastos também dificultarão o PNE que vier a substituir o atual, pois vigem até 2036. Os dados do INEP (2020), de monitoramento da meta 20 do PNE (sobre financiamento da educação), expõe uma proporção de gasto público em educação pública de 5,1\% em 2015 e 5,0\% em 2018; quer dizer, houve decréscimo no indicador e, por conseguinte, chegar a um gasto público em educação pública correspondente a 7\% do PIB em 2019 e a 10\% em 2024 (metas do PNE), não se efetivou e nada indica que se efetivará, respectivamente.

Despesas em diversas funções orçamentárias, entre elas a Função Educação, no período 2014-2020, e estimativa de despesa orçamentária para 2021, foram examinadas por Amaral (2021). Na Função Educação, houve redução de R \$ 37,0 bilhões comparando-se 2020 com 2014, o que representou -28,5\%. Nelson Amaral expõem redução de despesas também nas funções Cultura, Gestão Ambiental, Ciência e Tecnologia; na Saúde, houve crescimento em 2020, em decorrência da pandemia de Covid-19, porém o autor demonstrou a forte queda na previsão orçamentária para 2021. Em contraponto, houve crescimentos: na Função Encargos Especiais, dos recursos financeiros associados ao refinanciamento da dívida e dos associados ao pagamento de juros, encargos e amortização da dívida, bem como na Função Defesa Nacional. Com isso, o autor conclui que estas foram áreas priorizadas pelo Executivo e pelo Legislativo federais na vigência do Teto de Gastos.

Frente a este quadro regressivo respaldado na política de austeridade fiscal, em outubro de 2020 a Coalizão Direitos Valem Mais lançou Nota Técnica (DIREITOS VALEM MAIS, 2020) em que são mostrados decréscimos da aplicação de recursos federais em várias áreas de política social, frente aos quais é feita uma proposta de piso mínimo emergencial para as áreas de Educação, Saúde, Assistência Social e Segurança Alimentar. A fundamentação de tal proposta é a observância do princípio constitucional de proibição de retrocesso e a adoção de 
medidas para fazer frente ao crescimento do desemprego, da fome e da miséria, agudizado com a pandemia de Covid-19. Na educação, a Nota expõe a redução de recursos a partir de 2016 e é defendido um piso mínimo de 181,4 bilhões para 2021, contra 144,5 previstos no Projeto de Lei Orçamentária Anual (PLOA) para 2021, quer dizer, 36,9 bilhões de reais a mais.

No próximo segmento o foco é a execução orçamentária do FNDE e da Capes nas ações de assistência financeira da União na educação básica, a qual segue a tendência mais geral de queda das aplicações na Função Educação e em outras áreas sociais, anteriormente pontuada.

\section{Por dentro das despesas do FNDE e da Capes na educação básica}

O levantamento de dados foi realizado no Portal da Transparência da Controladoria Geral da União, no módulo “Orçamento da Despesa”. É possível realizar o download de planilha Excel, por ano e, nela, com o recurso de filtro, localizar as ações do FNDE e da Capes. Em ambas as ações orçamentárias foram filtradas as ações da subfunção "Educação Básica". Tanto Capes como FNDE atuam em outras subfunções, principalmente "Educação Superior", mas as ações desta foram desconsideradas. As despesas de cada ano, com exceção de 2020, especificadas por ação, tiveram seus valores atualizados pelo IPCA para dezembro de 2020, para fins de comparação dos valores da série. A maior parte das ações aparece nos sete anos, todavia, algumas não passíveis de inserção nas ações especificadas foram alocadas na categoria "Outros" e são identificadas nas notas da Tabela 1. As transferências das cotas estaduais e municipais do salário-educação são uma repartição de receita, automática, com relativa estabilidade e, por isso, são apresentados dados com e sem esta transferência. Igualmente, a complementação da União ao Fundeb possui critério bem objetivo - no mínimo $10 \%$ dos recursos de contribuição dos governos subnacionais ao Fundo - e, por isto, também são apresentados dados que excluem esta ação.

A Tabela 1 reúne todas as ações e nela é detalhada, nas notas, a composição da categoria "outros" e alguns agrupamentos que foram realizados para fins de correspondência de algumas ações dentro do período. 
Tabela 1 - Despesas do FNDE e da Capes em Ações de Assistência Financeira da União à Educação Básica, Brasil - 2014-2020 (em R \$ 1,00 de 2020)

\begin{tabular}{|c|c|c|c|c|c|c|c|c|}
\hline Ações/Total & 2014 & 2015 & 2016 & 2017 & 2018 & 2019 & 2020 & $\begin{array}{l}\text { Dif. 2014- } \\
2020(\%)\end{array}$ \\
\hline Complementação da União ao Fundeb & $12.243 .725 .740,74$ & $13.262 .423 .532,92$ & $13.677 .765 .239,43$ & $14.605 .422 .726,64$ & $14.950 .103 .054,95$ & $16.114 .945 .889,26$ & $12.731 .488 .809,54$ & $4 \%$ \\
\hline Dinheiro Direto na Escola (PDDE) & 2.925.392.297,64 & $1.844 .414 .719,10$ & $1.536 .795 .984,07$ & $1.551 .891 .073,33$ & $1.770 .218 .025,29$ & 1.128.027.940,22 & $1.347 .420 .933,73$ & $-54 \%$ \\
\hline Apoio ao Transporte do Escolar (Pnate) & $801.584 .400,37$ & $716.590 .514,48$ & $659.318 .399,55$ & $652.337 .495,44$ & $725.260 .755,69$ & $736.431 .363,45$ & $720.000 .000,00$ & $-10 \%$ \\
\hline Apoio à Alimentação Escolar na Educação Básica (PNAE) & $5.098 .358 .103,40$ & 4.697.636.867,78 & $3.995 .747 .941,92$ & 4.415.651.763,75 & 4.387.753.821,96 & 4.176.412.592,70 & $4.306 .399 .876,34$ & $-16 \%$ \\
\hline Produção, Aquisição e Distribuiç̧ão de Livros e I & & & & & & & & \\
\hline Didáticos (PNLD) & $\begin{array}{r}1.547 .233 .526,93 \\
2.67 .54565,36\end{array}$ & $486.237 .275,21$ & $1.366 .923 .372,78$ & $913.471 .052,37$ & $\begin{array}{r}1.378 .667 .746,47 \\
53462580021\end{array}$ & $913.800 .876,24$ & $\begin{array}{r}1.025 .323 .403,51 \\
15709641600\end{array}$ & $-34 \%$ \\
\hline $\begin{array}{l}\text { Apoio ao Desenvolvimento da Educação Básica } \\
\text { Aquisicão de Vé́culos para o Transporte Escolar na Educacão }\end{array}$ & & & & & 534.625.890,21 & & $157.986 .416,00$ & $-41 \%$ \\
\hline Básica - Caminho da Escola & $35.415 .801,62$ & - & $177.842 .471,57$ & $9.469 .474,72$ & $27.511 .554,20$ & - & $3.553 .409,65$ & $-90 \%$ \\
\hline Apoio à Infraestrutura para a Educa & 664.929 .760 .87 & 233.081 .108 .26 & 387.626 .415 .42 & 41.193 .494 .06 & 492.855 .959 .21 & $52.392 .149,61$ & 110.083 .501 .04 & $-83 \%$ \\
\hline Apoio à Manutenção da Educação Infantil & $48.140 .094,25$ & $49.356 .701,72$ & $45.543 .826,96$ & $107.521 .835,88$ & $86.059 .475,18$ & $84.049 .410,66$ & $24.389 .530,15$ & $-49 \%$ \\
\hline Apoio à Implantaç̃o de Escolas para a Educacão Infantil & $130.277 .908,37$ & $12.639 .840,41$ & $36.526 .255,01$ & $11.239 .704,69$ & $899.453,55$ & 4.151.813,33 & 44.393.386,52 & $-66 \%$ \\
\hline Apoio à Alfabetização e EJA (*) & $279.683 .801,60$ & $53.144 .607,21$ & $252.407 .403,03$ & $73.171 .221,06$ & $25.357 .551,38$ & $772.308 .440,30$ & - & $-100 \%$ \\
\hline Concessão de Bolsas e Auxílio Financeiro na EJA (**) & $65.174 .744,45$ & $35.802 .249,27$ & $127.538 .689,82$ & $17.637 .859,33$ & $32.515 .485,44$ & $73.686,35$ & - & $-100 \%$ \\
\hline $\begin{array}{l}\text { Transferência das cotas estaduais e municipais do salário } \\
\text { educação }\end{array}$ & 14.321.582.259,25 & 13.475.247.313,53 & $12.586 .580 .873,48$ & $12.596 .763 .656,44$ & 12.858.624.659,11 & $11.656 .940 .960,42$ & $11.041 .959 .448,24$ & $-23 \%$ \\
\hline Concessão de Bolsas de Apoio à Educação Básica (Capes) & $2.482 .543 .609,39$ & $2.345 .555 .946,44$ & $1.133 .441 .555,37$ & 914.717.938,87 & $514.217 .218,26$ & $18.732 .326,99$ & $257.492 .341,35$ & $-90 \%$ \\
\hline $\begin{array}{l}\text { Apoio à Capacitação e Formação Inicial e Continuada para a } \\
\text { Educação Básica (Capes) }\end{array}$ & $129.072 .392,56$ & $29.834 .850,19$ & $92.639 .625,30$ & $42.400 .004,99$ & $31.278 .994,61$ & 14.912.411,13 & $14.859 .827,33$ & $-88 \%$ \\
\hline Outros & $259.566 .624,60$ & 19.943.917,91 & $\underbrace{-}$ & $5.999 .204,66$ & & - & - & $-100 \%$ \\
\hline Total & 41.300.526.672,43 & 37.268.669.383,77 & 36.083.447.543,23 & 599.699,11 & 37.815.949.645,52 & 36.256.047.881,72 & 512.998.714,72 & $-24 \%$ \\
\hline
\end{tabular}

Valores atualizados pelo IPCA/IBGE de dezembro de 2020.

(*) Apoio à Alfabetização, à Educação de Jovens e Adultos e a Programas de Elevação de Escolaridade, com Qualificação Profissional e Participação Cidadã.

(**) Concessão de Bolsas e Auxílio Financeiro na Educação de Jovens e Adultos e em Programas de Elevação de Escolaridade Integrados à Qualificação Profissional e à Participação.

Notas: (1) "Outros", em 2014, inclui as ações "Implantação e Adequação de Estruturas Esportivas Escolares", "Integração da Comunidade no Espaço Escolar, Promoção da Saúde na Escola e Combate à Violência, à Discriminação e à Vulnerabilidade Social" e "Tecnologia da Informação e Comunicação para a Educação Básica"; (2) "Outros, em 2015 e 2017, inclui a ação "Implantação e Adequação de Estruturas Esportivas Escolares"; (3) em 2014 e 2015, a ação "Apoio à Alfabetização e EJA" corresponde às ações "Apoio à Alfabetização" e "Elevação da Escolaridade e Qualificação Profissional - Projovem"; (4) em 2014, a ação "Apoio ao Desenvolvimento da Educação Básica" inclui "Apoio ao Desenvolvimento da Educação Básica" e "Apoio ao Desenvolvimento da Educação Básica nas Comunidades do Campo, Indígenas, Tradicionais, Remanescentes de Quilombos e das Temáticas Cidadania e Direitos Humanos, Meio Ambiente e das Políticas de Inclusão dos Alunos com Deficiência".

Fonte: Portal da Transparência da CGU - Orçamento da Despesa orçamento realizado.

No total, de 2015 a 2020 não foi retomado ou ultrapassado o patamar de recursos de 2014, oscilando entre 36-37 bilhões de reais entre 2015 e 2019, com acentuado decréscimo em 2020; neste ano, a despesa total correspondeu a apenas 76\% daquela de 2014 (R \$ 9,7 bilhões a menos $)^{5}$. Das 16 categorias especificadas na Tabela 1 , somente a complementação da União ao Fundeb não apresenta redução entre o primeiro e o último ano da série, embora o valor de 2020 seja menor do que as despesas do período 2015-2019, considerada esta fonte de dados. Os quatro programas chamados de "universais - PDDE, Pnae, Pnate e PNLD - têm redução considerados os anos de 2014 e 2020, sendo o PDDE o programa com maior redução, da ordem de $-54 \%$ (R \$ 1,58 bilhão a menos). O PDDE, Pnae e Pnate são programas cujas referências para repasse de recursos (per capita/estudantes ou valores fixos) foram objeto de congelamento, ou acréscimos reduzidos e, no que concerne ao PDDE, houve reformulações das ações agregadas/integradas, com maior focalização destas ou descontinuidades. 
As ações de assistência financeira voluntária da União que passam pelo Plano de Ações Articuladas - Apoio ao Desenvolvimento da Educação Básica, Caminho da Escola e Apoio para a Infraestrutura da Educação Básica - apresentam enormes oscilações no período e grande redução quando comparados 2020 e 2014, com destaque para o Caminho da Escola, com -90\% de recursos.

As duas ações específicas da educação infantil - Apoio à Manutenção e Apoio à Implantação de Escolas de Educação Infantil ${ }^{6}$ - também tiveram oscilações de monta e, tendo em conta o primeiro e o último ano, o decréscimo de recursos foi da ordem de $49 \%$ e $66 \%$, respectivamente $^{7}$. A evolução da execução orçamentária das ações da EJA $^{8}$ confirma o lamentável descrédito desta modalidade da educação básica nas ações federais de assistência à educação básica, também expresso nos fatores de ponderação de matrículas relativamente mais baixos no âmbito do Fundeb ${ }^{9}$. No ano de 2020 não constam despesas realizadas na fonte utilizada para o levantamento.

As duas ações alocadas na Capes como Unidade Orçamentária - Concessão de Bolsas de Apoio à Educação Básica, Apoio à Capacitação e Formação Inicial e Continuada para a Educação Básica - seguiram também uma trajetória descontínua no intervalo de tempo examinado. Juntando as duas ações, houve redução de 90\% em 2020, comparado a 2014 (2,3 bilhões de reais a menos). A ação Concessão de Bolsas de Apoio à Educação Básica, que contou com mais de R \$ 2,0 bilhões em 2014 e 2015, declinou enormemente, com irrisórios R\$ 19 milhões em 2019, subindo para $\mathrm{R} \$ 257,5$ milhões em 2020, o que representa somente em torno de $10 \%$ dos valores de 2014 e 2015.

Nos gráficos 1 e 2 são apresentadas as despesas do FNDE e da Capes, e uma segunda categoria: no Gráfico 1, as despesas sem a ação de transferência das cotas subnacionais do salário-educação; no Gráfico 2, as despesas sem as ações de transferência das cotas subnacionais do salário-educação e complementação da União ao Fundeb. As duas ações são previstas constitucionalmente e suas regras são bastante precisas em relação ao montante mínimo de recursos, ou seja, não sofrem influência de decisões governamentais e este é o motivo para fazer este exercício.

\footnotetext{
${ }^{6}$ São ações previstas na Lei n ${ }^{\circ}$ 12.722/2012, portanto, parte da assistência financeira obrigatória da União na educação básica. A ação “Apoio à Manutenção da Educação Infantil” (Brasil Carinhoso) foi prevista no art. $4^{\circ}$ desta Lei, todavia, foi revogada pela Medida Provisória n 1.061/2021, a qual prevê, em substituição a esta ação, a implantação do "auxílio criança cidadã", a ser concedido a famílias elegíveis, que tenham crianças entre zero e 48 meses, para pagamento de creches privadas; um grande retrocesso, desde várias perspectivas, entre elas a desconsideração das aplicações feitas pela própria União, e pelos municípios, durante anos, na expansão da educação infantil pública. A MP, no momento de escrita deste artigo, está em apreciação no Congresso Nacional. Oxalá este dispositivo não seja aprovado.

A respeito destas ações, ver: Fineduca (2021); Farenzena, Müller e Felix (2020).

${ }^{8}$ No âmbito da EJA, vigem as leis $n^{\circ} 11.692 / 2008$ (Projovem) e 10.880/2004 (Brasil Alfabetizado e Programa de Apoio aos Sistemas de Ensino para Atendimento à Educação de Jovens e Adultos), as quais autorizam transferências de recursos da União aos estados e municípios. Não foi possível obter maiores informações sobre as intermitências nas despesas realizadas, porém é assunto que merece ser detidamente examinado.

${ }^{9}$ A respeito do decréscimo de matrículas e dos recursos da EJA no âmbito federal e das redes estaduais e municipais, ver Pinto (2021).
} 
Gráfico 1 - Despesas do FNDE e da Capes em Ações de Assistência Financeira da União à Educação Básica, com e sem a Transferência de Recursos das Cotas Estaduais e Municipais da Salário-Educação (SE), Brasil - 20142020 (em R \$ bilhões de 2020)

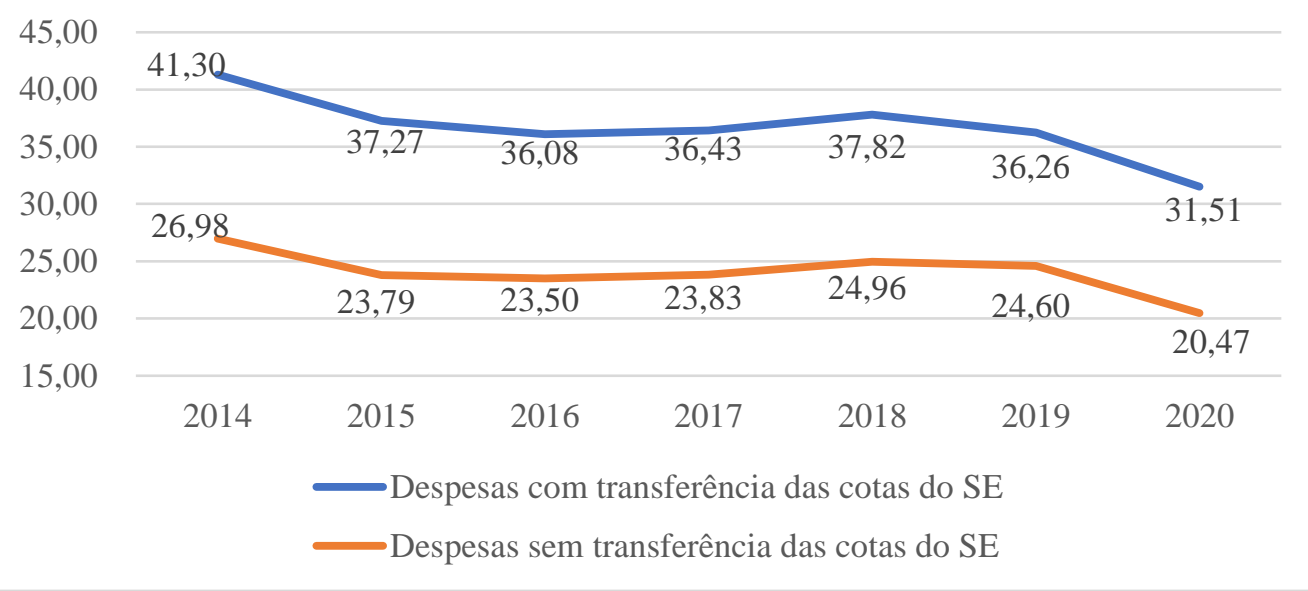

Fonte: Portal da Transparência da CGU - Orçamento da Despesa (orçamento realizado) Valores atualizados pelo IPCA/IBGE de dezembro de 2020.

Gráfico 2 - Despesas do FNDE e da Capes em Ações de Assistência Financeira da União à Educação Básica, com e sem a Transferência de Recursos das Cotas Estaduais e Municipais da Salário-Educação (SE) e a Complementação da União ao Fundeb (COUN Fundeb), Brasil - 20142020 (em R \$ bilhões de 2020)

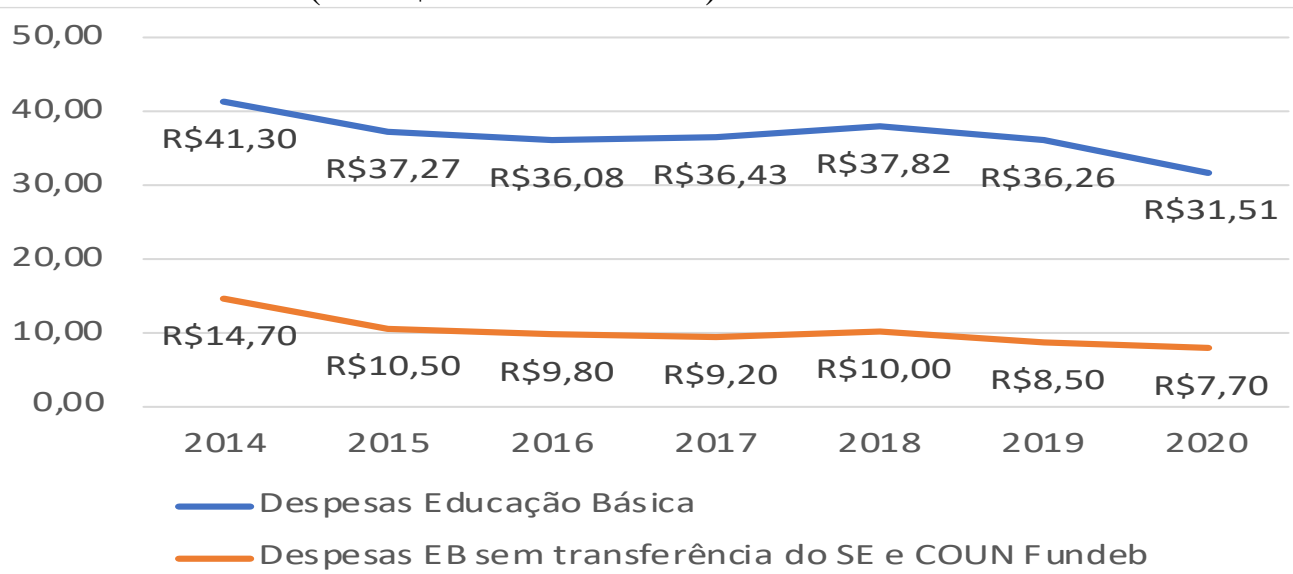

Fonte: Portal da Transparência da CGU - Orçamento da Despesa (orçamento realizado) Valores atualizados pelo IPCA/IBGE de dezembro de 2020.

Sem considerar as cotas estaduais e municipais do salário-educação (Gráfico 1) que constituem, de fato, uma repartição de receita, as despesas realizadas do FNDE ficam bem mais baixas. Em 2020, foram R \$ 20,47 bilhões, contra R \$ R 26,98 em 2014 - R \$ 6,5 bilhões a menos. O Gráfico 2 oferece um retrato mais realista do impacto da política de austeridade fiscal na assistência financeira federal na educação básica. Desconsideradas a repartição do salárioeducação e a complementação ao Fundeb (Gráfico 2), o valor de 2020 representa pouco mais 
da metade daquele de 2014, a perda é de R \$ 7,0 bilhões. Nos anos de 2015 a 2018 houve queda em relação a 2014, mas esta acentuou-se nos dois últimos anos da série.

Cabe comentar que a principal fonte de financiamento das ações de assistência financeira da União à educação básica é a parcela federal da contribuição do salário-educação (excetuada a complementação ao Fundeb). De acordo com o estudo de Lutz (2020), e considerando os anos abrangidos neste texto, até 2017 esta fonte não financiava o PNAE; de 2014 a 2017 as ações com maior volume de recursos bancadas pelo salário-educação cota federal, foram o PDDE, Pnate, PNLD e concessão de bolsas para a educação básica. A partir de 2018, o salário-educação passa a financiar o Pnae.

Excluídas a repartição das cotas estaduais e municipais, e a complementação ao Fundeb (pois vedado o uso do salário-educação para tal), conforme dados do Gráfico 2 e Tabela 1, o PNAE é a ação com maior volume de recursos e tudo indica que a decisão política de o financiar com recursos do salário-educação incluiu o desprovimento ou subtração de recursos das outras ações, o que é alinhado à política de austeridade fiscal. A linha inferior do Gráfico 2 demonstra bem este movimento.

Por fim, na Tabela 2 é apresentada uma estimativa de valor por matrícula/aluno da educação básica pública estadual e municipal das despesas executadas pela Capes e FNDE no período. Embora as ações tenham públicos-alvo diferenciados, esta construção pode ser importante, como certa medida da participação da União no financiamento da educação básica. As cotas subnacionais do salário-educação foram excluídas em função de seu caráter de repartição de receita; a complementação ao Fundeb até 2020 era restrita a alguns estados e por este motivo não foi computada. 
Tabela 2 - Valor por Aluno das Redes Estaduais, Municipais e do Distrito Federal das Despesas do FNDE e da Capes em Ações de Assistência da União na Educação Básica (EB), Brasil - 2024-2020 (excluídas a Complementação da União ao Fundeb e as transferências das cotas estaduais e municipais do salário-educação)

\begin{tabular}{r|r|r|r}
\hline \multicolumn{1}{l|}{ Ano } & $\begin{array}{l}\text { Despesas FNDE e Capes } \\
\text { na Educação Básica* } \\
\text { (R\$ dez. 2020) }\end{array}$ & $\begin{array}{l}\text { Matrículas Estaduais, } \\
\text { Municipais e do DF na } \\
\text { Educação Básica }\end{array}$ & $\begin{array}{l}\text { Valor por Aluno (R\$ } \\
\text { dez. 2020) }\end{array}$ \\
\hline 2014 & $14.735 .218 .672,43$ & 40.383 .845 & 364,9 \\
2015 & $10.530 .998 .537,33$ & 39.362 .550 & 267,5 \\
2016 & $9.819 .101 .430,32$ & 39.441 .813 & 249,0 \\
2017 & $9.225 .413 .316,04$ & 39.324 .550 & 234,6 \\
2019 & $10.007 .221 .931,45$ & 39.049 .540 & 256,3 \\
2020 & $8.484 .161 .032,05$ & 38.334 .654 & 221,3 \\
\hline
\end{tabular}

*Foram excluídas despesas da complementação da União ao Fundeb e transferências das cotas estaduais e municipais do salário-educação.

Fontes: despesas - Portal da Transparência da CGU, orçamento da despesa (orçamento realizado); matrículas - sinopses estatísticas da educação básica, do INEP.

Conforme os dados da Tabela 2, mesmo com o decréscimo de matrículas o valor por aluno das ações do FNDE e da Capes consideradas baixou. Do primeiro para o último ano da série, a diferença é de $\mathrm{R} \$ 161,7$ reais (-44\%). Assim como os recursos (Gráfico 2), o movimento de queda ficou mais acentuado em 2019 e 2020. Os recursos efetivamente decresceram, seja no total, seja no valor aluno. Diante da política de austeridade fiscal, é bem possível que, na agenda da política de financiamento da educação sobre a assistência da União, haja uma concentração do debate na repartição dos recursos com os entes subnacionais e tipos de escolas, que dizer, no aumento da equidade, secundarizando o debate da escancarada necessidade de mais recursos.

\section{Comentário final}

Os recursos da assistência financeira da União à educação básica decaíram no período examinado. Desconsideradas a repartição do salário-educação com os governos subnacionais e a complementação da União ao Fundeb, os recursos despencaram. Estes movimentos ensejam uma reflexão sobre um possível aumento da responsabilidade dos governos subnacionais no financiamento educacional. A diminuição de recursos federais repercute na ponta, quer dizer, nas mantenedoras públicas e nas escolas. Por exemplo, o decréscimo, em valores reais, do PNAE ou das ações de assistência da educação infantil impõe mais despesas para os municípios. Os recursos do PDDE transferidos às escolas não podem mais garantir o mesmo patamar de 
despesa de 2014, o que pode gerar mais demandas às mantenedoras ou providências, no âmbito das comunidades escolares, para geração de recursos próprios. Um beco aparentemente sem saída em que a educação pública é desvalorizada e submetida à lógica da política de austeridade.

A prática da política de assistência, abordada neste artigo por meio da execução orçamentária, desnuda o imenso desafio com que vão se deparar os setores comprometidos com a realização do direito à educação com qualidade social para concretizar o Custo AlunoQualidade como parâmetro para a atuação da União na garantia de padrões de qualidade do ensino. Imenso, não impossível.

\section{Referências}

AMARAL, Nelson Cardoso. Dois anos de desgoverno - os números da desconstrução. A Terra é Redonda, 08 de abril de 2021. Disponível em: https://aterraeredonda.com.br/doisanos-de-desgoverno-os-numeros-da-desconstrucao/. Acesso: maio de 2021.

BRASIL. Constituição da República Federativa do Brasil de 1988. Diário Oficial da União, Brasília, 05 out. 1988. Disponível em:

http://www.planalto.gov.br/ccivil_03/constituicao/constituicao.htm. Acesso contínuo.

BRASIL. Lei $n^{o}$ 10.880, de 09 de junho de 2004. Institui o Programa Nacional de Apoio ao Transporte do Escolar - PNATE e o Programa de Apoio aos Sistemas de Ensino para Atendimento à Educação de Jovens e Adultos, dispõe sobre o repasse de recursos financeiros do Programa Brasil Alfabetizado [...].

BRASIL. Lei $n^{o} 11.692$, de 10 de junho de 2008. Dispõe sobre o Programa Nacional de Inclusão de Jovens - Projovem [...].

BRASIL. Lei $n^{o}$. 12.722, de 03 de outubro de 2012. [....] dispõe sobre o apoio financeiro da União aos Municípios e ao Distrito Federal para ampliação da oferta da educação infantil; e dá outras providências.

BRASIL. Lei no 13.005, de 25 de junho de 2014. Aprova o Plano Nacional de Educação PNE e dá outras providências. Diário Oficial da União, Brasília, 2014. Disponível em: http://www.planalto.gov.br/ccivil_03/_ato2011-2014/2014/lei/113005.htm. Acesso em: maio 2021.

BRASIL. Lei no 14.113, de 25 de dezembro de 2020. Regulamenta o Fundo de Manutenção e Desenvolvimento da Educação Básica e de Valorização dos Profissionais da Educação (Fundeb), de que trata o art. 212-A da Constituição Federal; revoga dispositivos da Lei $\mathrm{n}^{\mathrm{o}}$ 11.494, de 20 de junho de 2007; e dá outras providências. Diário Oficial da União, Brasília, 2020. Disponível em: http://www.planalto.gov.br/ccivil_03/_Ato2019-2022/2020/Lei/L14113 .htm. Acesso em: junho 2021.

BRASIL. Medida Provisória no 1.061, de 09 de agosto de 2021. Institui o Programa Auxílio Brasil e o Programa Alimenta Brasil, e dá outras providências. 
CAVALCANTI, Cacilda Rodrigues. Configurações da política de assistência da União para a oferta de educação básica pós golpe de 2016. FINEDUCA - Revista de Financiamento da Educação, v. 09, n. 19, p. 1-13, 2019. DOI: http://dx.doi.org/10.22491/fineduca-2236-5907v9-90083.

CAVALCANTI, Cacilda Rodrigues. Tensões federativas no financiamento da educação básica: equidade, qualidade e coordenação federativa na assistência técnica e financeira da União. Belo Horizonte: UFMG, 2016. Tese (Doutorado em Educação) - Programa de PósGraduação em Conhecimento e Inclusão Social em Educação, Faculdade de Educação, Universidade Federal de Minas Gerais, Belo Horizonte, 2016.

COALIZÃO Direitos Valem Mais. LDO/LOA 2021 e PEC 188: Piso mínimo emergencial para serviços essenciais, desmonte do Estado pela PEC do Pacto Federativo e necessidade de mudanças urgentes nas regras fiscais. São Paulo, Nota Técnica, set. 2020.

CRUZ, Rosana Evangelista da. Pacto federativo e financiamento da educação: a função supletiva e redistributiva da União - o FNDE em destaque. São Paulo: USP, 2009. Tese (Doutorado em Educação) - Programa de Pós-Graduação em Educação, Faculdade de Educação, Universidade de São Paulo, São Paulo, 2009.

DWECK, Esther; ROSSI, Pedro; OLIVEIRA, Ana Luíza Matos. Economia pós-pandemia: desmontando os mitos da austeridade fiscal e construindo um novo paradigma econômico. São Paulo: Autonomia Literária, 2020. Disponível em: https://pedrorossi.org/wpcontent/uploads/2020/11/Economia-Po\%CC\%81s-Pandemia-compactado.pdf. Acesso em: jul. 2021.

FARENZENA, N. A assistência financeira da União às políticas educacionais locais. Retratos da Escola, Brasília, v. 6, n. 10, p. 105-117, jan./jun. 2012a.

FARENZENA, N. Relações intergovernamentais nas políticas de educação básica no Brasil: a assistência da União aos governos subnacionais em foco. Revista Uruguaya de Ciencia Política, v. 21, p. 183-202, 2012b.

FARENZENA, N.; MULLER, K. S.; FELIX, N. F. F. Financiamento e oferta da educação infantil no Rio Grande do Sul (2009-2019). In: ROCHA, D. B.; ROYER, H. (Org.). Educação infantil: uma visão multidisciplinar. Porto Alegre: ESGC Publicações; TCE/RS, 2020. p. 177210.

FINEDUCA. Por que o salário-educação não pode ser fonte da complementação da União ao Fundeb. Manifestação. São Paulo, mar. 2020a. Disponível em: https://fineduca.org.br/ 2020/03/27/por-que-o-salario-educacao-nao-pode-ser-fonte-da-complementacao-da-uniao-aofundeb/. Acesso em: 21 maio 2021.

FINEDUCA. Em defesa de novos recursos para a complementação da União ao Fundeb. São Paulo, abr. 2020b. Disponível em: Disponível em: https://fineduca.org.br/2020/04/13/emdefesa-de-novos-recursos-para-complementacao-da-uniao-ao-fundeb/. Acesso: abril de 2021.

FINEDUCA. A política de educação infantil no Brasil: das garantias legais ao financiamento do atendimento público. São Paulo, jul. 2021. Disponível em: 
https://fineduca.org.br/2021/07/09/a-politica-de-educacao-infantil-no-brasil-das-garantiaslegais-ao-financiamento-do-atendimentopublico/. Acesso: agosto de 2021.

INEP. Instituto Nacional de Estudos e Pesquisas Anísio Teixeira. Relatório do $3^{\circ}$ Ciclo de Monitoramento das Metas do Plano Nacional de Educação - 2020. Brasília: Inep, 2020. LASCOUMES, Pierre; LE GALÈS, Patrick. Sociologie de l'acion publique. Paris: Armand Colin, 2007.

LUTZ, Diego. Trajetórias do salário-educação (1997-2018) como política de financiamento da educação. Porto Alegre: UFRGS, 2020. Tese (Doutorado em Educação) - Programa de Pós-Graduação em Educação, Faculdade de Educação, Universidade Federal do Rio Grande do Sul, Porto Alegre, 2020.

MACHADO, Maria Goreti Farias; FARENZENA, Nalú. Delineamentos normativos da política de financiamento da educação básica brasileira. In: CHAVES, Neusa Batista; Flores, Maria Luíza Rodrigues. Formação de Gestores Escolares para a Educação Básica: avanços, retrocessos e desafios frente aos 20 anos de normatização da gestão democrática na LDBEN. Porto Alegre: Evangraf, Escola de Gestores, 2016, p. 173-190.

MARTINS, Paulo de Sena. O financiamento da educação básica como política pública. Revista Brasileira de Política e Administração da Educação, v. 26, p. 497-514, 2010.

MULLER, Pierre. Les politiques publiques. Paris : PUF, 2006.

O’DONNELL, Guilhermo. Democracia, agencia y estado: teoría com intención comparativa. Buenos Aires, Prometeo Libros, 2010. p. 205.

PINTO, José Marcelino de Rezende. As Esperanças Perdidas da Educação de Jovens e Adultos com o Fundeb. FINEDUCA - Revista de Financiamento da Educação, v. 11, n. 14, p. 1-21, 2021. DOI: http://dx.doi.org/10.22491/2236-5907111438.

PELLANDA, Andressa; CARA, Daniel. Educação na pandemia: oferta e financiamento remotos. In: DWECK, Esther; ROSSI, Pedro; OLIVEIRA, Ana Luíza Matos. Economia póspandemia: desmontando os mitos da austeridade fiscal e construindo um novo paradigma econômico. São Paulo: Autonomia Literária, 2020, p. 183-189. Disponível em: https://pedrorossi.org/wp-content/uploads/2020/11/Economia-Po\%CC\%81s-Pandemiacompactado.pdf. Acesso em: jul. 2021.

ROSSI, Pedro; OLIVEIRA, Ana Luíza Matos de; ARANTES, Flávio; DWECK, Esther. Austeridade fiscal e o financiamento da educação no Brasil. Educ. Soc., Campinas, v.40, e0223456, 2019. DOI: 10.1590/ES0101-73302019223456

THOENIG, Jean-Claude. Politique publique. In : BOUSSAGUET, Laurie; JACQUOT, Sophie ; RAVINET, Pauline. Dictionnaire des politiques publiques. Paris: Sciences Po - Les Presses, 2006, p. 328-335. 